\title{
Esophageal resection in Austria-preparing a national registry
}

\author{
Matthias Paireder · Reza Asari · Wolfgang Radlspöck · Anna Fabbri · Andreas Tschoner · Reinhold Függer · \\ Johannes Zacherl · Sebastian F. Schoppmann
}

Received: 29 June 2021 / Accepted: 30 June 2021 / Published online: 11 August 2021

(C) The Author(s) 2021

\begin{abstract}
Summary
Background Esophageal resection is a technically challenging procedure. Despite improvements in perioperative management and outcome, it is still associated with considerably high morbidity and mortality rates even if performed in high-volume centers. This study aimed to shed light on the results of routine patient care in three representative referral centers concerning caseload and surgical and oncological outcomes.

Methods This study is a retrospective, multicenter, national-wide analysis of a newly established database including perioperative and long-term outcome data from three referral centers in Austria.
\end{abstract}

\footnotetext{
M. Paireder · R. Asari · S. F. Schoppmann ( $\bowtie)$

Department of General Surgery, Upper-GI-Service

Comprehensive Cancer Center, Gastroesophageal

Tumor Unit, Medical University of Vienna,

Spitalgasse 23, 1090 Vienna, Austria

sebastian.schoppmann@meduniwien.ac.at

W. Radlspöck · J. Zacherl $(\bowtie)$

Department of Surgery, St. Josef Hospital of Vienna,

Auhofstraße 189, 1130 Vienna, Austria

johannes.zacherl@sjk-wien.at
}

A. Fabbri · A. Tschoner $\cdot$ R. Függer $(\square)$

Department of General, Visceral, Thoracic, Vascular and

Transplantation Surgery, Ordensklinikum Linz, Johannes Kepler University Linz, Sailerstaette 4, 4010 Linz, Austria reinhold.fuegger@ordensklinikum.at

\section{R. Függer}

Johannes Kepler University Linz,

Altenbergerstraße 69, 4040 Linz, Austria

\section{J. Zacherl}

Fakultät für Medizin, Sigmund Freud Privatuniversität Wien, Sigmund Freud Platz 3, 1020 Wien, Austria
Results In a 6-year study period (2013-2018), 411 patients were eligible for analysis. The indication for esophageal resection was esophageal adenocarcinoma in 299 (72.7\%) patients and esophageal squamous cell carcinoma in $90(21.9 \%)$ patients. The abdominothoracic approach $(70.1 \%)$ was the most common operation, followed by transhiatal extended gastrectomy (14.8\%) and a thoracic-abdominal-cervical approach (8.5\%). Most patients $(77.9 \%)$ underwent neoadjuvant therapy (chemotherapy $45.3 \%$, radiochemotherapy in $32.6 \%$ ). A minimally invasive approach was chosen in $25.3 \%$. Major complications and mortality were seen in $21.7 \%$ and $2.9 \%$, respectively. The 1-year survival rate was $84 \%$, 3-year survival $60 \%$, and 5-year survival was $52 \%$. The pooled overall median survival was 110 months (95\% CI 33.97-186.03).

Conclusion This first publication of the Austrian Society of Esophageal Surgery shows that the outcome of esophageal surgery for cancer in Austria compares well with that of renowned international centers. However, a more comprehensive approach including as many national centers as possible will improve outcome research, offer quality management, and improve patient safety. The study group invites all Austrian institutions performing esophagectomy to participate in the initiative.

Keywords Outcome $\cdot$ Morbidity $\cdot$ Esophageal carcinoma - Clinical database - Esophagectomy

\section{Main novel aspects}

1. This is the most extensive study so far demonstrating multicenter results of esophageal surgery in Austria.

2. The authors show that the current treatment and surgical approach, morbidity, and oncological results are comparable to international registries. 
3. This work should be a basis for creating a more significant, more comprehensive registry for esophageal surgery in Austria.

\section{Introduction}

Surgery is still the mainstay for curative treatment of esophageal cancers [1]. Notably, for locally advanced stages, multimodal therapy has gained significant importance $[2,3]$. Although perioperative therapy does not impair morbidity after surgery, esophageal resection is still associated with high morbidity and mortality rates [4-6].

To improve morbidity and oncological outcome, esophageal surgery was suggested to be preferably performed in high-volume centers [7]. Implementation of such caseload requirements reduced the number of hospitals performing esophageal resections, expecting to improve outcomes [8]. In 2013 a caseload threshold of at least five esophagectomies per year was introduced in Austria, and elevated to a minimum of 10 procedures 1 year later on. Currently, there are ten Austrian centers performing esophagectomies regularly.

A minimally invasive approach in esophageal surgery was introduced to reduce the incisional trauma, improve the postoperative pulmonal condition, and allow faster recovery and possibly better quality of life at an equal oncological outcome [9-11]. Multiple trials demonstrated that minimally invasive esophagectomy (MIE) showed comparable oncological results with reduced postoperative morbidity and improved functional recovery [10,12, 13]. Despite the beneficial aspects of MIE, many cases are required to overcome the learning curve [14].

This study aimed to assess the treatment numbers and the surgical and oncological outcome in three high-volume referral centers representative for esophageal cancer surgery in Austria. Moreover, implementation of MIE and centralization of surgery is assessed and compared with current evidence.

\section{Materials and methods}

\section{Registry}

This study is a retrospective, multicenter, national analysis of a newly established database including patient data of three high-volume referral centers in Austria. The data were prospectively collected in each center and entered into the registry after pseudonymization. All consecutive patients who received esophageal surgery in the 6 years between 2013 to 2018 were included. One center started in 2014 and did not include transhiatal extended gastrectomies. The indication for surgery was either an esophageal malignancy (adenocarcinoma $[\mathrm{AC}]$, esophageal squamous cell carcinoma [ESCC], gastrointestinal stromal tumor [GIST], sarcoma, neuroendocrine carcinoma) or a benign indication such as leiomyoma or complex GERD. The tumor location of adenocarcinomas was classified following the Siewert classification of adenocarcinoma of the esophagogastric junction (AEG) [15]. All other tumors were classified into suprabifurcal, infrabifurcal, and cervical locations.

\section{Surgery}

An esophageal surgery was defined as either abdominothoracic resection (Ivor-Lewis procedure), thoracic-abdominal-cervical approach (McKeown procedure), transhiatal esophagectomy (Orringer procedure), jejunal interposition operation (Merendino procedure), transhiatal extended gastrectomy for AEG II tumors, or anastomotic resection with esophagojejunostomy. Hybrid minimally invasive esophagectomy (MIE) was defined as a laparoscopic formation of the gastric tube combined with an open thoracic approach. Total MIE was defined as laparoscopic gastric tube formation and thoracoscopy for the thoracic phase. Morbidity was classified according to the Clavien-Dindo (C/D) classification [16]. According to recent publications a Clavien-Dindo grade IIIb or higher was classified as a major complication [11]. For more details, see Table 2.

Patients were followed up on a 3-monthly basis for the first 2 years and then every 6 months until year 5 after surgery, followed by yearly visits. In order to optimize data accuracy and reduce the number of patients lost to follow-up, patients were contacted to evaluate the current status if the information was missing. Overall survival (OS) and recurrence-free interval (RFI) were defined as the period from the operation until death or recurrence of disease, respectively. For analysis of OS and RFI, only malignant indications were used.

The study was approved by the ethics committee (EK 1310/2018) of the Medical University of Vienna. Individual informed consent was not acquired due to the study design and national regulations.

\section{Statistics}

Age is described as mean and standard deviation (SD). Other continuous variables are described as medians and quartiles due to non-normal distributions. Interquartile range (IQR) was stated when applicable. Body mass index (BMI) was calculated by dividing weight in kilograms by height in meters squared. Categorical variables are described as counts and percentages. Overall survival and the recurrencefree interval were estimated using the Kaplan-Meier method. For comparison, the log-rank test was used. A $p$-value $<0.05$ is considered statistically significant. A $95 \%$ confidence interval $(95 \% \mathrm{CI})$ is reported if computable. SPSS (IBM Corp. Released 2020. IBM SPSS Statistics for Macintosh, version 27.0. Armonk, NY, USA) was used for statistical analysis. 
Table 1 Demographic and preoperative details

\begin{tabular}{|c|c|}
\hline Variable & All $(n=411)$ \\
\hline Age, years ${ }^{\mathrm{a}}$ & $63.1(11.4)$ \\
\hline \multicolumn{2}{|l|}{ Gender } \\
\hline Male & 338 (82.2) \\
\hline Female & $73(17.8)$ \\
\hline Body mass index, $\mathrm{kg} / \mathrm{m}^{2 \mathrm{~b}}$ & $25.3(22.7-28.7)$ \\
\hline Stent before operation & $31(7.5)$ \\
\hline Dysphagia before operation & $206(50.1)$ \\
\hline Weight loss before operation ${ }^{c}$ & $125(30.4)$ \\
\hline \multicolumn{2}{|c|}{$\begin{array}{l}\text { Values in parentheses are percentages unless indicated otherwise } \\
\text { avalues are mean (standard deviation) } \\
\text { bvalues are median (interquartile range) } \\
\text { cany involuntary weight loss reported by the patient }\end{array}$} \\
\hline
\end{tabular}

Table 2 Perioperative details and morbidity

\begin{tabular}{l|l|}
\hline Variable & All ( $n=411)$ \\
\hline Operation type & \\
\hline Ivor-Lewis & $288(70.1)$ \\
\hline McKeown & $35(8.5)$ \\
\hline Orringer & $17(4.1)$ \\
\hline Transhiatal extended gastrectomy & $61(14.8)$ \\
\hline Merendino & $4(1)$ \\
\hline Other (e.g., anastomotic resection) & $6(1.5)$ \\
\hline Surgical approach & \\
\hline Open & $304(74.0)$ \\
\hline Hybrid MIE & $100(24.3)$ \\
\hline Total MIE & $4(1)$ \\
\hline Laparoscopic assisted other & $3(0.7)$ \\
\hline Number of examined lymph nodes & \\
\hline Clavien-Dindo classification & $25(17-34)$ \\
\hline 0 & \\
\hline 1 & $224(54.5)$ \\
\hline 2 & $21(5.1)$ \\
\hline 3a & $44(10.7)$ \\
\hline 3b & $33(8.0)$ \\
\hline $4 a$ & $64(15.6)$ \\
\hline $4 b$ & $9(2.2)$ \\
\hline 5 & $4(1)$ \\
\hline Anastomotic leakage & $12(2.9)$ \\
\hline Pulmonary complication & $58(14.1)$ \\
\hline ICU stay (days) & $56(13.6)$ \\
\hline Hospital stay (days) & \\
\hline Values in parentheses are percentages unless indicated otherwise \\
\hline MIE minimally invasive esophagectomy, ICU intensive care unit \\
avalues are median (interquartile range) & \\
\hline & $6(4-8)$ \\
\hline
\end{tabular}

\section{Results}

\section{Patients}

Between 2013 and 2018, 411 patients were eligible for this analysis. The mean age was 63.1 (SD 11.4) years, and $338(82.2 \%)$ patients were male. The median body mass index at the time of surgery was 25.3 (IQR 22.7-28.7) $\mathrm{kg} / \mathrm{m}^{2}$. The most frequent in- dication for esophageal resection was an esophageal malignancy: adenocarcinoma in 299 (72.7\%) patients and esophageal squamous cell carcinoma in $90(21.9 \%)$ patients. Beyond that, other indications ( $n=22,5.2 \%$ ) were neuroendocrine carcinoma, highgrade dysplasia, gastrointestinal stromal tumor, and complex gastroesophageal reflux disease (GERD). The majority of patients $(77.9 \%)$ received multimodal therapy before surgery. Chemotherapy was indicated in $186(45.3 \%)$ patients, and 134 (32.6\%) patients received radiochemotherapy before surgery. For more details, see Table 1.

\section{Operation}

The abdominothoracic esophageal resection (IvorLewis procedure: $n=288,70.1 \%$ ) was the most common operation, followed by transhiatal extended gastrectomy $(n=61,14.8 \%)$ and the thoracic-abdominal-cervical approach (McKeown procedure: $n=35$, 8.5\%). Other operations were transhiatal esophagectomy (Orringer procedure), jejunal interposition operation (Merendino procedure), and other (local) resections for non-malignancies in 17 (4.1\%), 4 (1\%), and $6(1.5 \%)$ patients, respectively. In total, $304(74 \%)$ of the operations were performed in an open technique, whereas $100(24.3 \%)$ and 4 (1\%) procedures were performed in a hybrid or total minimally invasive approach, respectively.

A histologically confirmed clear resection margin was achieved in 374 (91\%) patients. The median number of lymph nodes removed was 25 (IQR 17-34).

Major complications (Clavien-Dindo $>$ IIIa) were documented in $89(21.7 \%)$ patients. Fifty-eight patients $(14.1 \%)$ developed anastomotic leakage (AL), $56(13.6 \%)$ patients presented pulmonary complications. The median hospital stay was 17 days (IQR 11-21), and the median stay at the intensive care unit was 6 days (IQR 4-8). Overall hospital mortality was $2.9 \%$. For more perioperative details, see Table 2.

\section{Survival}

At a median follow-up of 24 (IQR 11-49) months, 1-year survival was $84 \%$, 3-year survival $60 \%$, and 5 -year survival was $52 \%$. The pooled median overall survival was 110 (95\% CI 33.97-186.03) months, and the median recurrence-free interval was not reached. There was no significant difference in overall survival and recurrence-free interval regarding histology, surgical approach, or extent of lymph node yield (Figs. 1, 2, 3, 4, 5 and 6).

Regarding non-TNM categories, there were significant differences in long-term survival: median overall survival and recurrence-free interval decreased significantly if a vascular, lymphatic, or perineural invasion was present (Fig. 7). For more tumor-related details, see Table 3 . 
Fig. 1 Kaplan-Meier analcording to tumor histology. A $p$-value $<0.05$ is considered statistically significant. n.s. non significant ysis of overall survival ac-

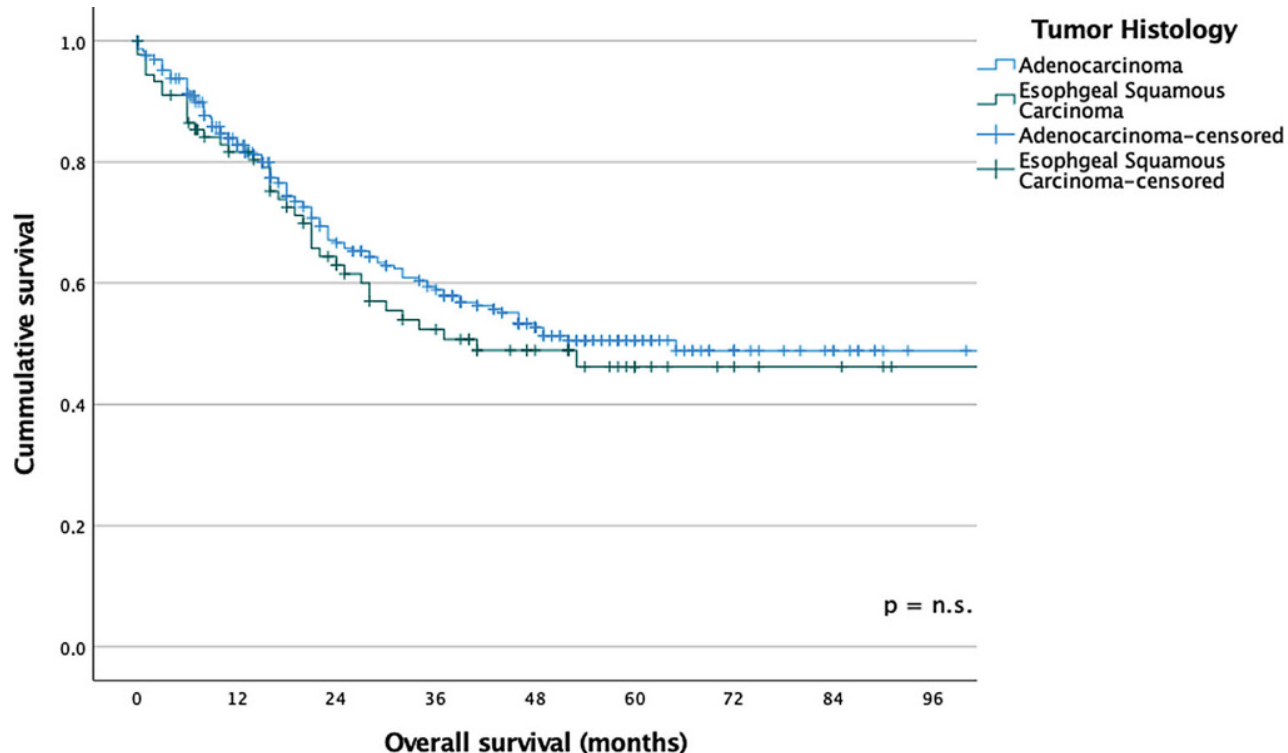

Fig. 2 Kaplan-Meier analysis of recurrence-free interval according to tumor histology. A $p$-value $<0.05$ is considered statistically significant. n.s. non significant

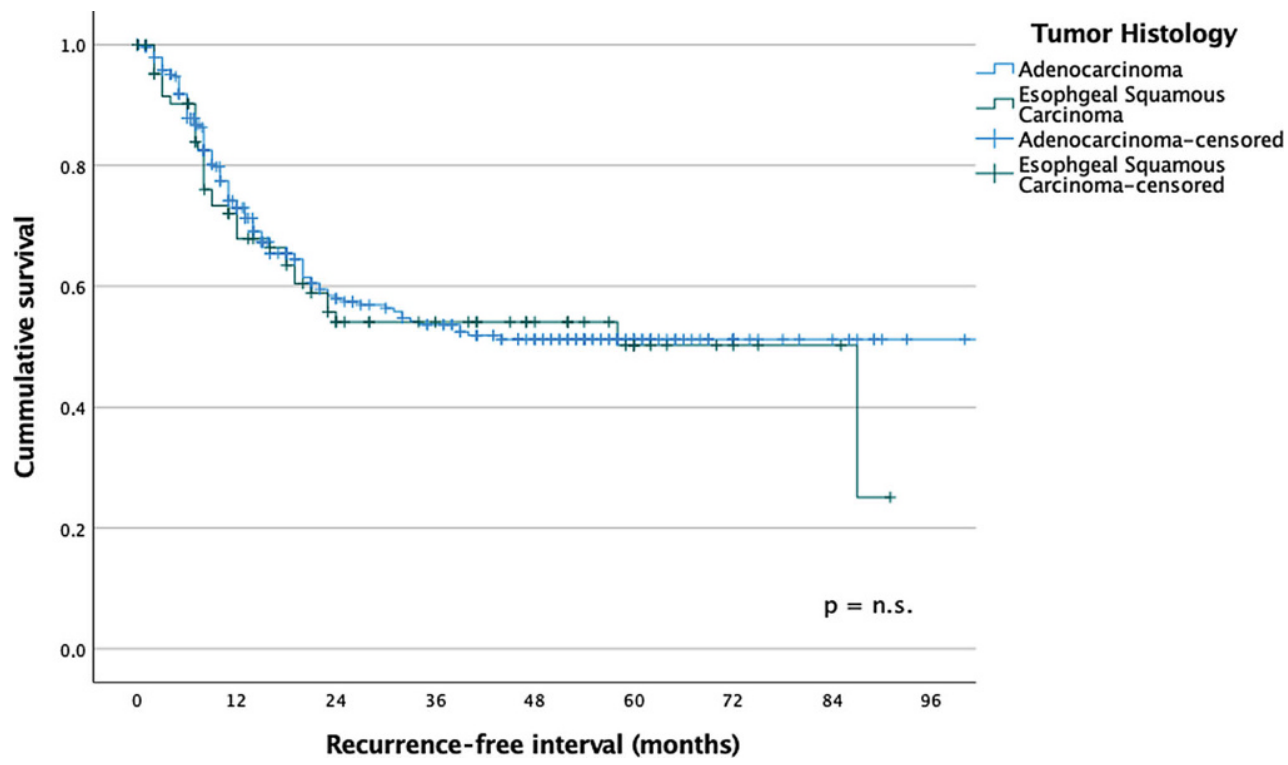

\section{Discussion}

First and foremost, this study is the largest to demonstrate multicenter results of esophageal surgery in Austria. We show that the current treatment and surgical approach, morbidity, and oncological results are tantamount to international registries.

Ivor-Lewis esophagectomy $(n=70.1 \%)$ was the most commonly performed operation, in line with the recent development towards the abdominal-thoracic approach. There is still an ongoing debate about the best surgical approach to resect and reconstruct the esophagus [17]. A randomized trial showed favorable survival results after a transthoracic approach in patients with lymph node involvement compared to the Orringer procedure [18]. After growing evidence that an intrathoracic anastomotic leakage was no longer associated with increased mortality, the transtho- racic Ivor-Lewis approach was increasingly suggested for carcinoma localized in the distal esophagus [19]. However, transhiatal esophagectomy seemed to lead to less pulmonary morbidity and this without survival disadvantages [20]. New evidence, again, favors the transthoracic approach in a large retrospective cohort [21].

Addressing the highly relevant benchmarks of morbidity and mortality, the major complication rate (C/D > IIIa) in this study was $21.7 \%$. This rate lies within published rates, which range from around $10 \%$ to up $34.9 \%[11,22]$. In general, the definition of morbidity (major/minor) and the use of the classification is very inhomogeneous throughout the literature [23]. This also applies to reporting and classification of anastomotic leakage (AL). The participating centers did not use the Esophageal Complications Consensus Group definition for AL in this study [24]. However, 
Fig. 3 Kaplan-Meier analysis of overall survival according to the surgical approach. A $p$-value $<0.05$ is considered statistically significant. n.s. non significant, OE open esophagectomy, MIE minimally invasive esophagectomy

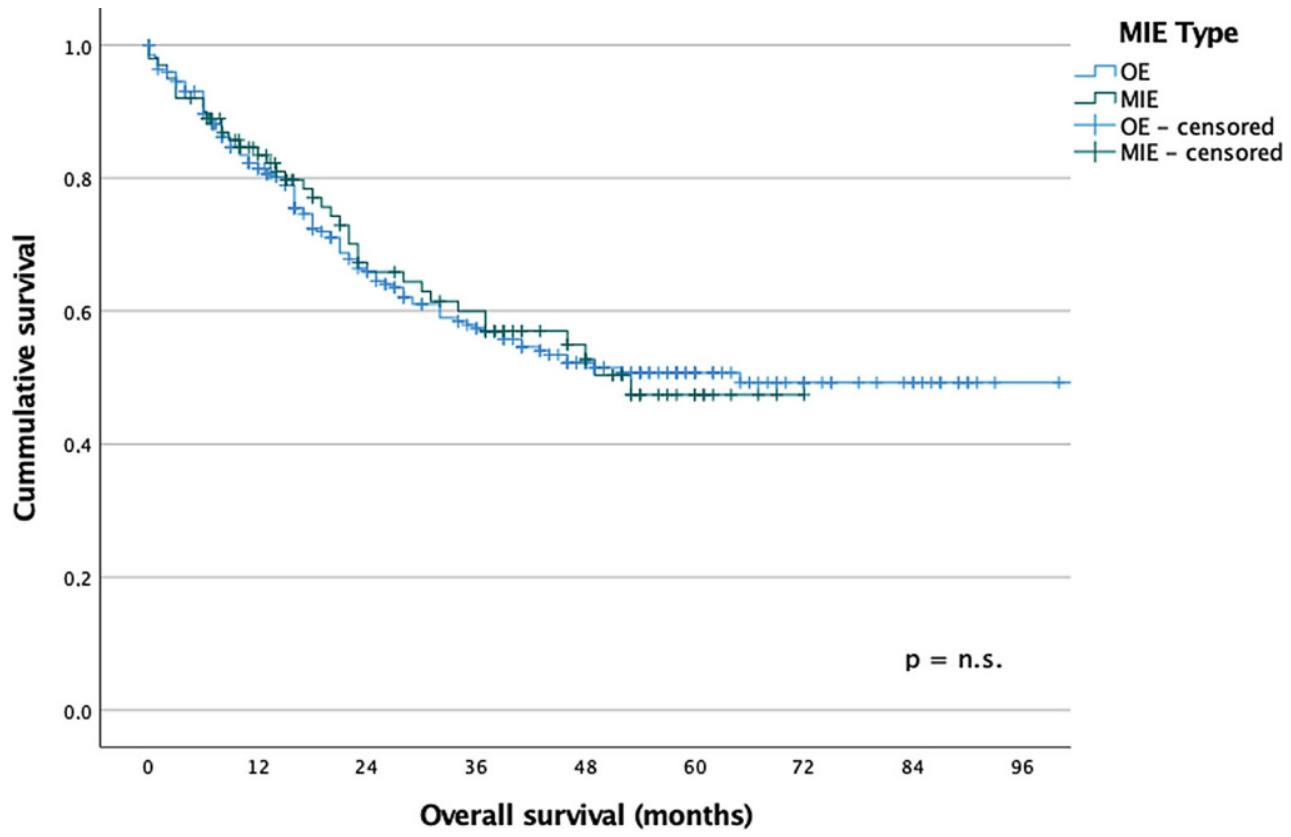

Fig. 4 Kaplan-Meier analysis of recurrence-free interval according to the surgical approach. A $p$-value $<0.05$ is considered statistically significant. n.s. non significant, $O E$ open esophagectomy, MIE minimally invasive esophagectomy

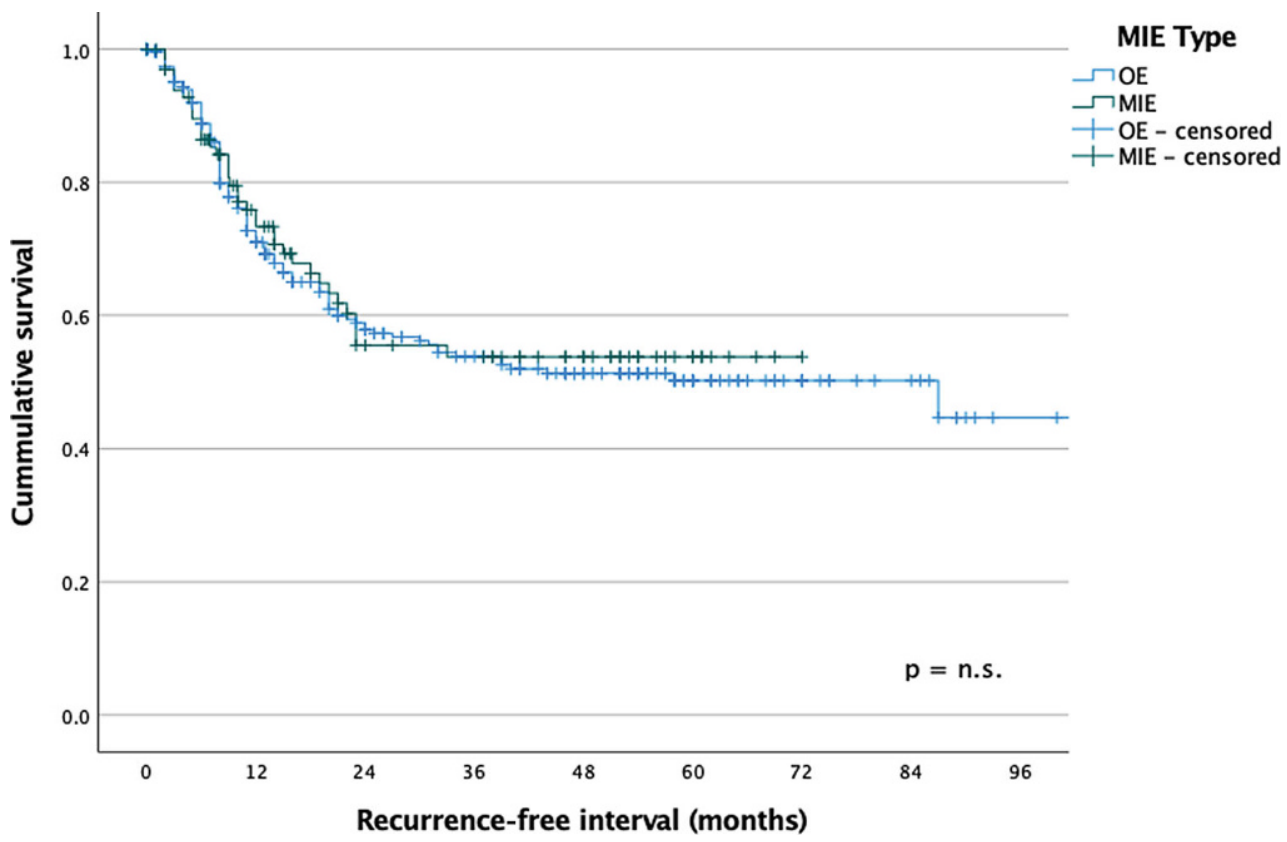

the reported AL rate of $14.1 \%$ lies within the published rates from $5-25 \%$ for cervical anastomosis and 5-16\% for thoracic anastomosis [23]. Still, the low rates published by Luketich et al. of $8.6 \%$ should be strived for [25]. Historically, esophageal resection was associated with a high mortality rate. Improvement of surgical technique as well as perioperative management could reduce mortality. However, the low rate of $2.9 \%$ is again comparable with other national data [26].

Centralization of esophageal surgery improves outcome [26, 27]. In many European countries like Sweden, the Netherlands, or Switzerland, centralization has already taken place $[8,26]$. There is still an ongoing debate about caseload requirements in Austria, which led to different regional regulations. Nevertheless, current level $2 \mathrm{a}$ evidence showing the impact of centralization of cancer surgery on postoperative mortality supports this development towards caseload requirements [28].

In this study, around $25 \%$ of the esophagectomies were done with a minimally invasive approach. As there is growing evidence about the clear benefit of MIE, it is to expect that this number will rise. Still, it is crucial to implement new surgical techniques in a well-structured manner, without jeopardizing patient safety. Experts advise having adequate support, proctoring, and the appropriate infrastructure to over- 
Fig. 5 Kaplan-Meier analysis of overall survival regarding lymph node yield $>\mathrm{mec}$ number of 25 . A $p$-value $<0.05$ is considered statistically significant. n.s. non significant, $L N$ lymph node

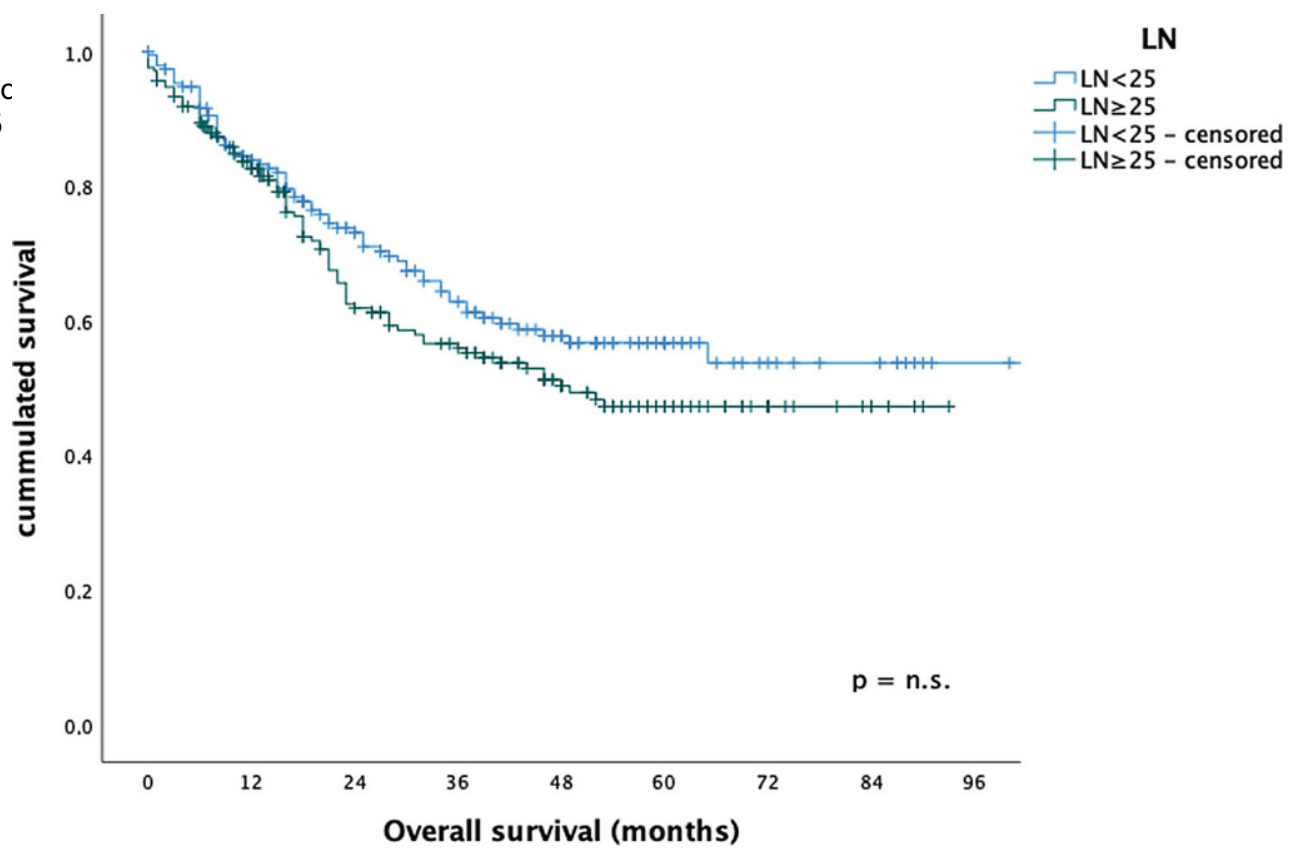

Fig. 6 Kaplan-Meier analysis of recurrence-free interval regarding lymph node yield $>$ median number of 25. A $p$-value $<0.05$ is considered statistically significant. n.s. non significant, $L N$ lymph node

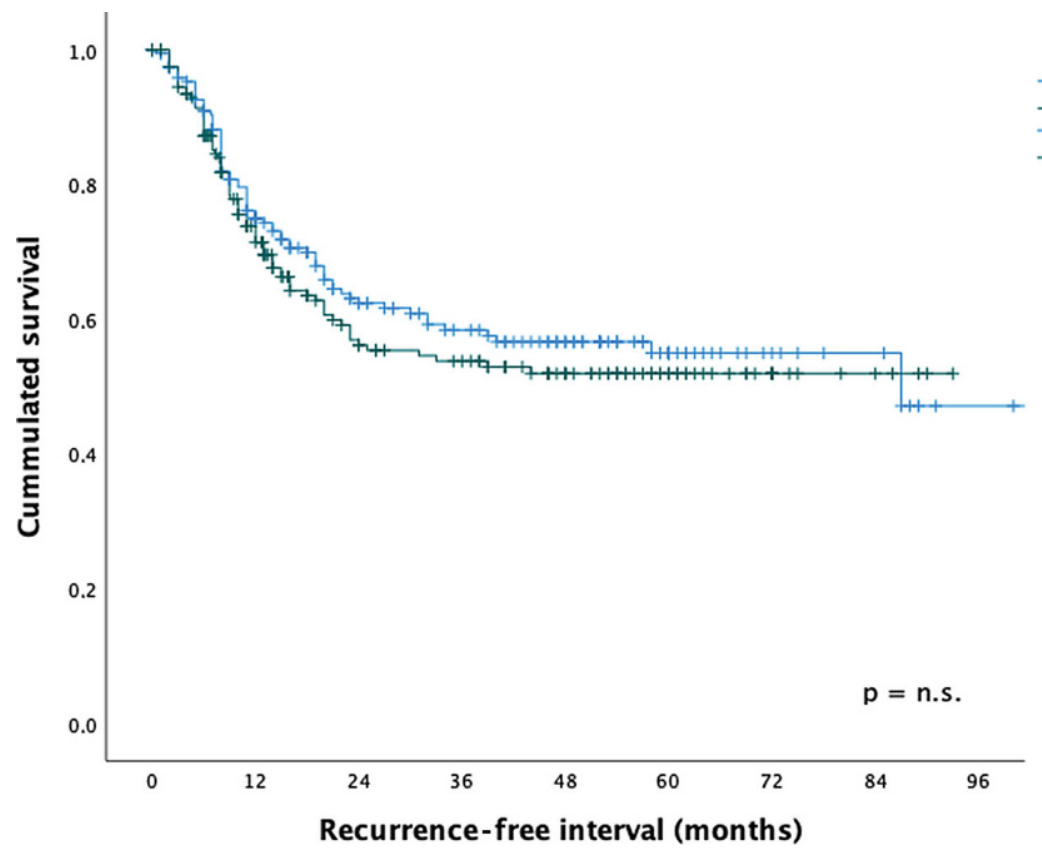

come a particular learning curve [14]. A recent multicenter study identified a substantial learning curve of 119 cases regarding anastomotic leakage in MIE [29].

The strength of this study is the multicenter approach and high treatment numbers. Furthermore, this work includes registry data exceeding the classical TNM categories. Such expanded oncological information like vascular, lymphatic, and perineural invasion and number of lymph nodes involved was also suggested for registries [30]. This will potentially refine prognostication and may direct future adjuvant therapy [30].
There are several limitations to address. First of all, this work is of a retrospective nature. The data extraction was performed locally in the particular centers and, therefore, challenging to standardize. Moreover, there are different approaches to classifying "soft" categories such as morbidity. To minimize this limitation, the centers used the Clavien-Dindo classification to categorize morbidity. A possible comprehensive registry should prospectively establish consensual reporting standards like those offered by the Esophageal Complications Consensus Group to overcome these limitations. 

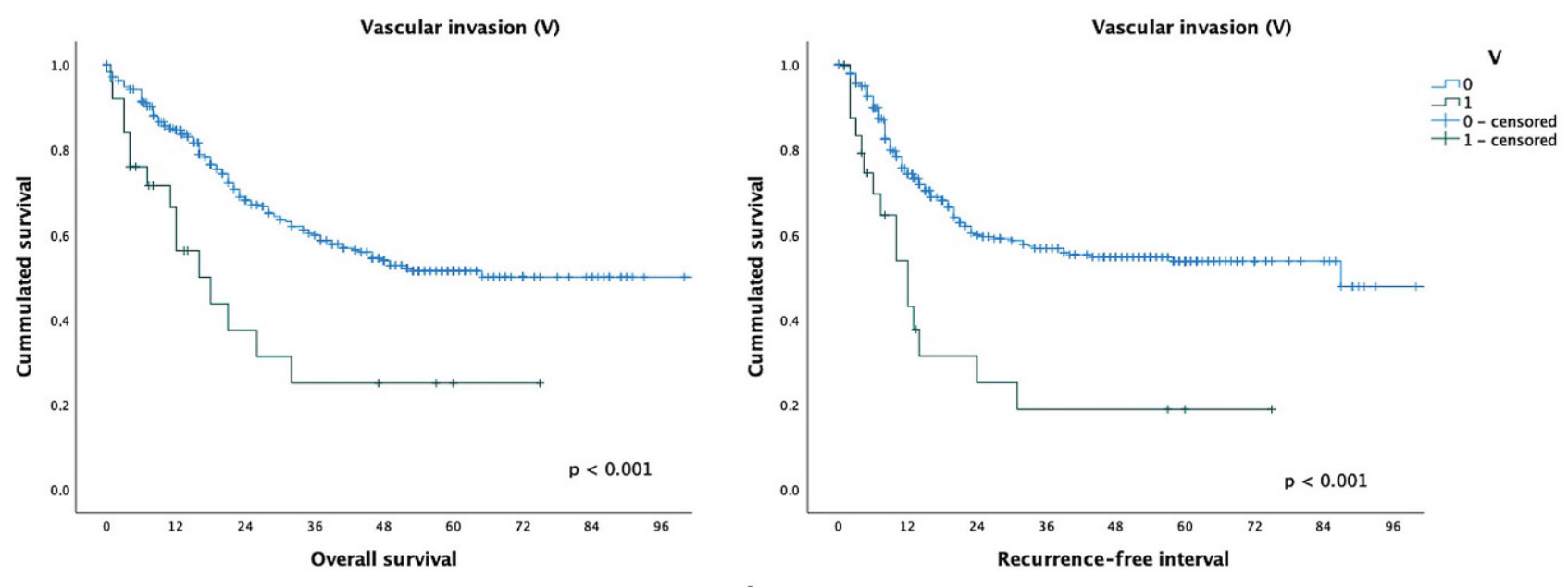

a

$$
\text { b }
$$
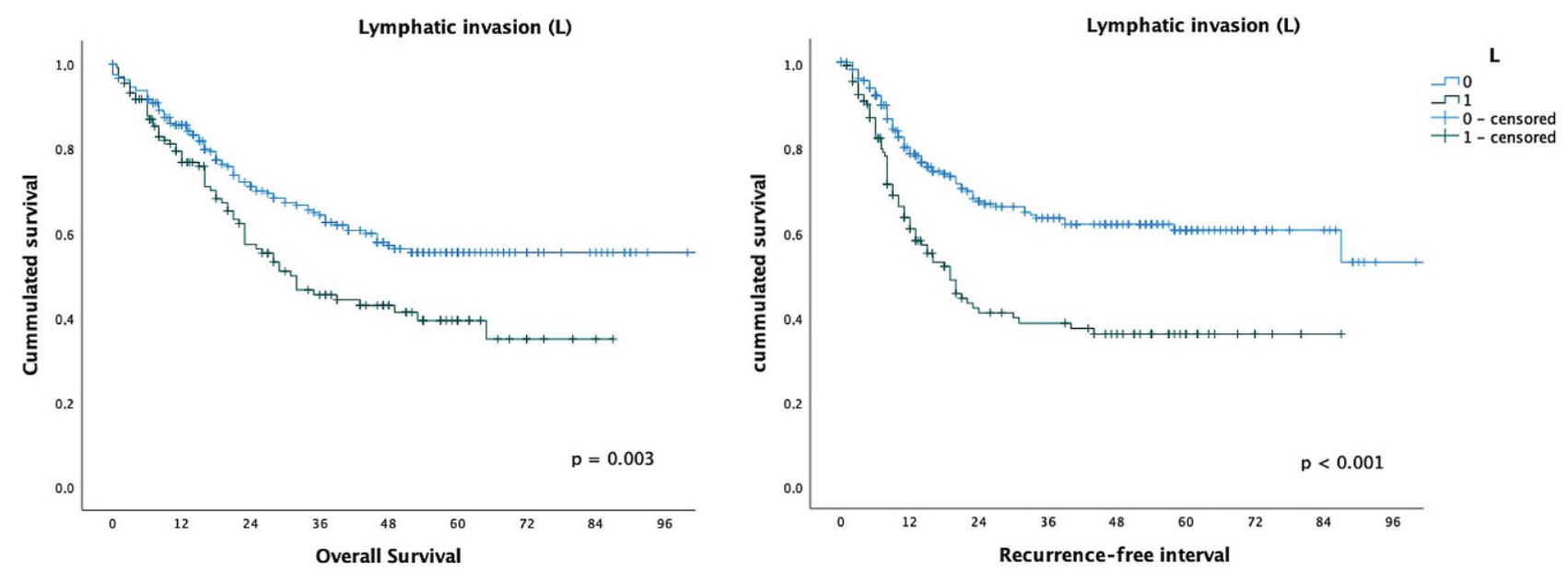

c

d
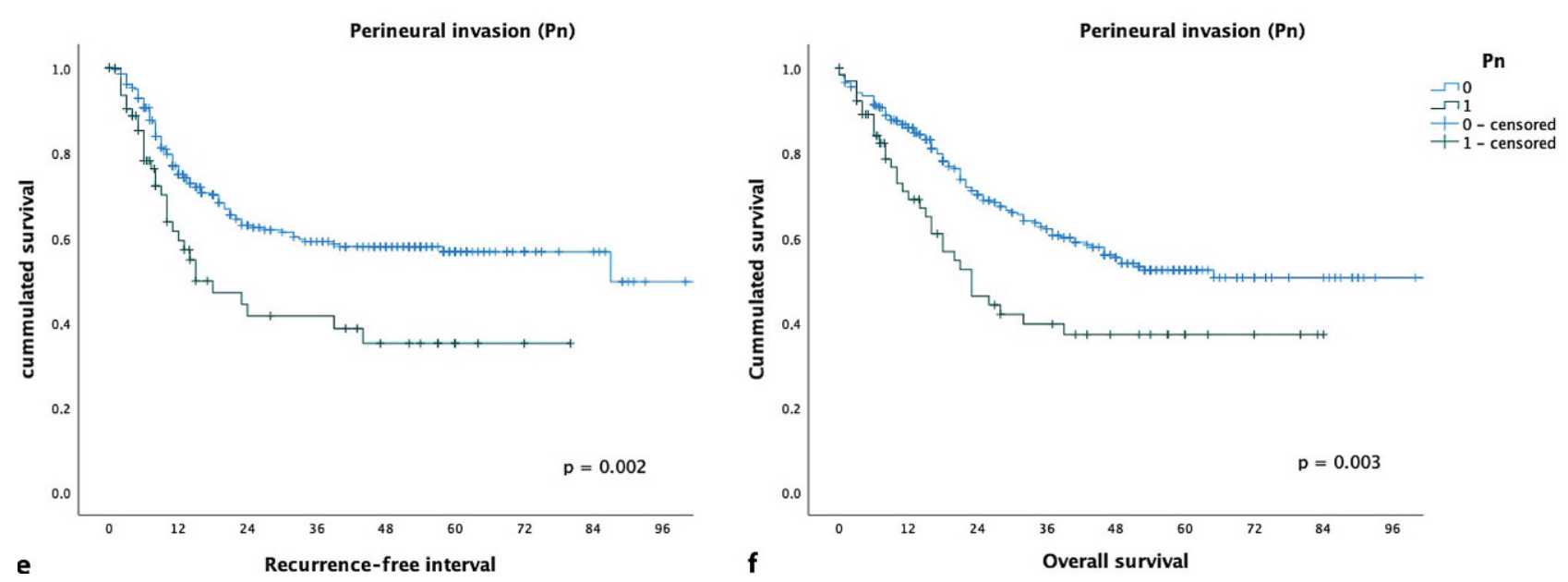

Fig. 7 Kaplan-Meier survival analysis for non-TNM categories: a overall survival (OS) for vascular invasion; b recurrence-free interval (RFI) for vascular invasion; c OS for lym-

phatic invasion; d RFI for lymphatic invasion e RFI for perineural invasion. $f$ OS for perineural invasion. A $p$-value $<0.05$ is considered statistically significant 
Table 3 Tumor-related details

\begin{tabular}{|c|c|}
\hline Variable & All $(n=411)$ \\
\hline \multicolumn{2}{|l|}{ Tumor location } \\
\hline ESCC above level of tracheal bifurcation & $40(9.7)$ \\
\hline ESCC below level of tracheal bifurcation & $54(13.1)$ \\
\hline Siewert type I & $197(47.9)$ \\
\hline Siewert type II & $73(17.8)$ \\
\hline Siewert type III & $26(6.3)$ \\
\hline Non-malignancies or GIST & $21(5.1)$ \\
\hline \multicolumn{2}{|l|}{ Tumor histology, no. (\%) } \\
\hline Adenocarcinoma & $299(72.7)$ \\
\hline Squamous cell carcinoma & $90(21.9)$ \\
\hline Neuroendocrine carcinoma & $1(0.2)$ \\
\hline High-grade dysplasia & $10(2.4)$ \\
\hline Gastrointestinal reflux disease & $9(2.1)$ \\
\hline Gastrointestinal stromal tumor & $2(0.5)$ \\
\hline \multicolumn{2}{|l|}{ Neoadjuvant treatment ${ }^{a}$} \\
\hline Chemotherapy & $186(47.7)$ \\
\hline Radiochemotherapy & $134(34.4)$ \\
\hline \multicolumn{2}{|l|}{ Tumor grading ${ }^{\mathrm{a}}$} \\
\hline Well differentiated (G1) & $12(3.1)$ \\
\hline Moderately differentiated (G2) & $126(32.3)$ \\
\hline Poorly differentiated (G3) & $199(51.0)$ \\
\hline Undifferentiated (G4) & $1(0.3)$ \\
\hline Gx & $7(1.8)$ \\
\hline \multicolumn{2}{|l|}{ Pathologic tumor stage $\mathrm{a}^{\mathrm{a}}$} \\
\hline T0 & $68(17.4)$ \\
\hline Tis (HGD) & $2(0.5)$ \\
\hline T1a & $26(6.7)$ \\
\hline $\mathrm{T} 1 \mathrm{~b}$ & $55(14.1)$ \\
\hline T2 & $65(16.7)$ \\
\hline T3 & $161(41.3)$ \\
\hline T4a & $11(2.8)$ \\
\hline T4b & $2(0.5)$ \\
\hline \multicolumn{2}{|l|}{ Pathologic nodal stage $\mathrm{a}^{\mathrm{a}}$} \\
\hline N0 & $222(56.9)$ \\
\hline N1 & $70(17.9)$ \\
\hline N2 & $58(14.9)$ \\
\hline N3 & $36(9.2)$ \\
\hline Missing information & $4(1.0)$ \\
\hline \multicolumn{2}{|l|}{ Pathological distant site ${ }^{\mathrm{a}}$} \\
\hline M0 & $378(96.7)$ \\
\hline M1 & $12(3.1)$ \\
\hline \multicolumn{2}{|l|}{ Surgical margin status ${ }^{\mathrm{a}}$} \\
\hline Clear & 364 (93.3) \\
\hline Microscopically involved (R1) & $24(6.2)$ \\
\hline Macroscopically involved (R2) & $2(0.5)$ \\
\hline \multicolumn{2}{|l|}{ Lymphatic invasion ${ }^{\mathrm{a}}$} \\
\hline LO & $249(63.8)$ \\
\hline L1 & $135(34.6)$ \\
\hline Missing information & $6(1.5)$ \\
\hline \multicolumn{2}{|l|}{ Vascular invasion ${ }^{\mathrm{a}}$} \\
\hline V0 & $359(92.1)$ \\
\hline V1 & $25(6.4)$ \\
\hline
\end{tabular}

Table 3 (Continued)

\begin{tabular}{ll} 
Variable & All $(n=411)$ \\
$\begin{array}{l}\text { Missing information } \\
\text { Perineural invasion }\end{array}$ & $6(1.5)$ \\
\hline Pn0 & \\
\hline Pn1 & $299(76.7)$ \\
\hline $\begin{array}{l}\text { Missing information } \\
\text { Values in parentheses are percentages. }\end{array}$ & $65(16.7)$ \\
$\begin{array}{l}\text { ESCC esophageal squamous cell carcinoma, HGD high grade dysplasia, } \\
\text { GIST gastrointestinal stromal tumor } \\
\text { anon-malignancies and GIST excluded }\end{array}$ & $26(6.7)$ \\
\hline $\begin{array}{l} \\
\text { non }\end{array}$
\end{tabular}

\section{Conclusion}

This first publication of this multicenter study group shows the current status of esophageal surgery in three high-volume centers in Austria. The outcome of esophageal surgery in this study is comparable with international benchmarks. However, a more comprehensive approach including as many national centers as possible will improve outcome research, offer quality management, and improve patient safety. Therefore, the study group aims to include all possible centers for esophageal surgery.

Author Contribution All authors contributed to the study's conception and design. Material preparation and data collection were performed by Matthias Paireder, Anna Fabbri, Andreas Tschoner, Reza Asari, Johannes Zacherl, and Wolfgang Radlspöck. Data analysis and interpretation were done by Matthias Paireder, Johannes Zacherl, Reinhold Függer, and Sebastian F. Schoppmann. Matthias Paireder wrote the first draft of the manuscript, and all authors commented on previous versions of the manuscript. All authors read and approved the final manuscript.

Funding Open access funding provided by Medical University of Vienna.

Conflict of interest M. Paireder, R. Asari, W. Radlspöck, A. Fabbri, A. Tschoner, R. Függer, J. Zacherl, and S.F. Schoppmann declare that they have no competing interests.

Open Access This article is licensed under a Creative Commons Attribution 4.0 International License, which permits use, sharing, adaptation, distribution and reproduction in any medium or format, as long as you give appropriate credit to the original author(s) and the source, provide a link to the Creative Commons licence, and indicate if changes were made. The images or other third party material in this article are included in the article's Creative Commons licence, unless indicated otherwise in a credit line to the material. If material is not included in the article's Creative Commons licence and your intended use is not permitted by statutory regulation or exceeds the permitted use, you will need to obtain permission directly from the copyright holder. To view a copy of this licence, visit http://creativecommons.org/licenses/by/4.0/.

\section{References}

1. Shah MA, Kennedy EB, Catenacci DV, Deighton DC, Goodman KA, Malhotra NK, et al. Treatment of locally advanced esophageal carcinoma: ASCO guideline. J Clin Oncol. 2020;38(23):2677-94. 
2. Al-Batran SE, Homann N, Pauligk C, Goetze TO, Meiler J, Kasper S, et al. Perioperative chemotherapy with fluorouracil plus leucovorin, oxaliplatin, and docetaxel versus fluorouracil or capecitabine plus cisplatin and epirubicin for locally advanced, resectable gastric or gastrooesophageal junction adenocarcinoma (FLOT4): a randomised, phase 2/3 trial. Lancet. 2019;393(10184):1948-57.

3. Toxopeus E, van der Schaaf M, van Lanschot J, Lagergren J, Lagergren P, van der Gaast A, et al. Outcome of patients treated within and outside a randomized clinical trial on neoadjuvant chemoradiotherapy plus surgery for esophageal cancer: extrapolation of a randomized clinical trial (CROSS). Ann Surg Oncol. 2018;25(8):2441-8.

4. Low DE, Kuppusamy MK, Alderson D, Cecconello I, Chang AC, Darling G, et al. Benchmarking complications associated with esophagectomy. Ann Surg. 2019;269(2):291-8.

5. Paireder M, Asari R, Kristo I, Rieder E, Zacherl J, Kabon B, et al. Morbidity in open versus minimally invasive hybrid esophagectomy (MIOMIE): Long-term results of arandomized controlled clinical study. Eur Surg. 2018;50(6):249-55.

6. Paireder M, Jomrich G, Kristo I, Asari R, Rieder E, Beer A, et al. Modification of preoperative radiochemotherapy for esophageal cancer (CROSS protocol) is safe and efficient with no impact on surgical morbidity. Strahlenther Onkol. 2020;196(9):779-86.

7. Birkmeyer JD, Siewers AE, Finlayson EV, Stukel TA, Lucas FL, Batista I, et al. Hospital volume and surgical mortality in the United States. NEngl J Med. 2002;346(15):1128-37.

8. Kaech M, Deutschmann E, Moffa G, Haak F, Bucher HC, KettelhackC, et al. Influence of the introduction of caseload requirements on indication for visceral cancer surgery in Switzerland. Eur J Surg Oncol. 2021. https://doi.org/10. 1016/j.ejso.2021.04.006.

9. Schoppmann SF, Prager G, Langer FB, Riegler FM, Kabon B, Fleischmann E, et al. Open versus minimally invasive esophagectomy: a single-center case controlled study. Surg Endosc. 2010;24(12):3044-53.

10. Mariette C, Markar SR, Dabakuyo-Yonli TS, Meunier B, Pezet D, Collet D, et al. Hybrid minimally invasive esophagectomy for esophageal cancer. N Engl J Med. 2019;380(2):152-62.

11. Wang H, Tang H, Fang Y, Tan L, Yin J, Shen Y, et al. Morbidity and mortality of patients who underwent minimally invasive esophagectomy after neoadjuvant chemoradiotherapy vs neoadjuvant chemotherapy for locally advanced esophageal squamous cell carcinoma: a randomized clinical trial. JAMA Surg. 2021. https://doi.org/10.1001/ jamasurg.2021.0133.

12. Biere SS, van Berge Henegouwen MI, Maas KW, Bonavina L, Rosman C, Garcia JR, et al. Minimally invasive versus open oesophagectomy for patients with oesophageal cancer: a multicentre, open-label, randomised controlled trial. Lancet. 2012;379(9829):1887-92.

13. Bartella I, Brinkmann S, Fuchs H, Leers J, Schlosser HA, Bruns CJ, etal. Two-stagehybridIvor-Lewis esophagectomy as surgical strategy to reduce postoperative morbidity for high-risk patients. Surg Endosc. 2021;35(3):1182-9.

14. Peng JS, Kukar M, Hochwald SN. ASO author reflections: overcoming the learning curve for minimally invasive esophagectomy. AnnSurg Oncol. 2020;27(8):3039-40.

15. SiewertJR, Stein HJ. Classification of adenocarcinoma of the oesophagogastricjunction. BrJSurg. 1998;85(11):1457-9.

16. Clavien PA, Barkun J, de Oliveira ML, Vauthey JN, Dindo D, Schulick RD, et al. The Clavien-Dindo classification of surgical complications: five-year experience. Ann Surg. 2009;250(2):187-96.
17. Martin LW, SwisherSG, HofstetterW, CorreaAM, Mehran RJ, Rice DC, et al. Intrathoracicleaks following esophagectomy are nolonger associated with increased mortality. Ann Surg. 2005;242(3):392-9. discussion399-402.

18. Omloo JM, Lagarde SM, Hulscher JB, Reitsma JB, Fockens $\mathrm{P}$, van Dekken $\mathrm{H}$, et al. Extended transthoracic resection compared with limited transhiatal resection for adenocarcinoma of the mid/distal esophagus: fiveyear survival of a randomized clinical trial. Ann Surg. 2007;246(6):992-1000. discussion 1000-1.

19. Allum WH, Bonavina L, Cassivi SD, Cuesta MA, Dong ZM, Felix VN, et al. Surgical treatments for esophageal cancers. Ann NYAcad Sci. 2014;1325:242-68.

20. Davies AR, Sandhu H, Pillai A, Sinha P, Mattsson F, Forshaw MJ, et al. Surgical resection strategy and the influence of radicality on outcomes in oesophageal cancer. Br J Surg. 2014;101(5):511-7.

21. Takahashi C, Shridhar R, Huston J, Blinn P, Maramara T, Meredith K. Comparative outcomes of transthoracic versus transhiatal esophagectomy. Surgery. 2021. https://doi.org/ 10.1016/j.surg.2021.02.036.

22. Nilsson K, Klevebro F, Rouvelas I, Lindblad M, Szabo E, Halldestam I, et al. Surgical morbidity and mortality from the multicenter randomized controlled NeoRes II trial: standard versus prolonged time to surgery after neoadjuvant chemoradiotherapy for esophageal cancer. Ann Surg. 2020;272(5):684-9.

23. Gujjuri RR, Kamarajah SK, Markar SR. Effect of anastomotic leaks on long-term survival after oesophagectomy for oesophageal cancer: systematic review and meta-analysis. Dis Esophagus. 2021. https://doi.org/10.1093/dote/ doaa085.

24. Low DE, Alderson D, Cecconello I, Chang AC, Darling GE, D'Journo XB, et al. International consensus on standardization of data collection for complications associated with esophagectomy: Esophagectomy Complications Consensus Group (ECCG). Ann Surg. 2015;262(2):286-94.

25. Luketich JD, Pennathur A, Franchetti Y, Catalano PJ, Swanson S, Sugarbaker DJ, et al. Minimally invasive esophagectomy: results of a prospective phase II multicenter trial-The eastern cooperative oncology group (E2202) study. Ann Surg. 2015;261(4):702-7.

26. Busweiler LAD, Jeremiasen M, Wijnhoven BPL, Lindblad M, Lundell L, van deVelde CJH, et al. International benchmarking in oesophageal and gastric cancer surgery. BJS Open. 2019;3(1):62-73.

27. Pasquer A, Renaud F, Hec F, Gandon A, Vanderbeken M, Drubay $\mathrm{V}$, et al. Is centralization needed for esophageal and gastric cancer patients with low operative risk?: A nationwide study. Ann Surg. 2016;264(5):823-30.

28. Grilli R, Violi F, Bassi MC, Marino M. The effects of centralizing cancer surgery on postoperative mortality: a systematic review and meta-analysis. J Health Serv Res Policy. 2021; https://doi.org/10.1177/13558196211008942.

29. van Workum F, Stenstra M, Berkelmans GHK, Slaman AE, van Berge Henegouwen MI, Gisbertz SS, et al. Learning curve and associated morbidity of minimally invasive esophagectomy: a retrospective multicenter study. Ann Surg. 2019;269(1):88-94.

30. Rice TW, Gress DM, Patil DT, Hofstetter WL, Kelsen DP, Blackstone EH. Cancer of the esophagus and esophagogastric junction-Major changes in the American Joint Committee on Cancer eighth edition cancer staging manual. CA Cancer JClin. 2017;67(4):304-17.

Publisher's Note Springer Nature remains neutral with regard to jurisdictional claims in published maps and institutional affiliations. 